\title{
Measurement of the Width of Attached Gingiva in An Indian Subpopulation
}

Dhalkari Chandulal, ${ }^{1}$ Wagatkar J ayshri, ${ }^{2}$ Neha Bansal ${ }^{3}$

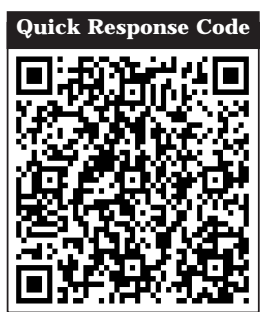

doi : $10.5866 / 2016.8 .10014$

${ }^{1}$ Associate Professor

2Senior Resident

Department of Periodontology Government Dental

College, Aurangabad.

${ }^{3}$ Assistant professor

Department of Oral Medicine and Radiology,

Government Dental College, Aurangabad.

\section{Article Info:}

Received: J anuary 8, 2016

Review Completed: February 10, 2016

Accepted: March 11, 2016

Available Online: May, 2016 (www.nacd.in)

(C) NAD, 2016 - All rights reserved

\section{Email for correspondence:}

dr.jayshriw@yahoo.com

\begin{abstract}
:
Background: Width of attached gingiva (WAG) is an important marker for diagnosis of periodontal disease. The aim of this study was to determine normal values of the width of attached gingiva in an Indian subpopulation.

Material and Methods: A total of 240 subjects were selected with healthy gingival tissue. WAG was measured.

Results: The mean values of attached gingiva varied in different areas of the mouth. The width of attached gingiva increases with increase in age and is found to be more in females than males.

Conclusion: WAG varies with age, gender and in different areas of the mouth. F urther studies should be done on periodontally healthy individuals in different populations to ascertain the value of WAG and further consider it as adequate or inadequate, thus helping in forming a better treatment plan.
\end{abstract}

Key words: Width of attached gingiva, age, sex, histochemical staining

\section{INTRODUCTION:}

According to Orban and Sicher, oral cavity is lined by three different kind of mucosa. Masticatory mucosa which includes covering of hard palate and gingiva of alveolar process, lining mucosa which include covering of lips, cheeks and vestibular fornix and specialized mucosa covering the dorsum of tongue. Each of this oral mucosa has its own clinical significances. Anatomically gingiva is divided into free, attached and interdental gingiva. Attached gingiva is a part of keratinized gingiva which aids in periodontium to increase resistance to external injury and contribute in stabilization of gingival margin against frictional forces. For many years the presence of an "adequate" zone of gingiva was considered critical for the maintenance of marginal tissue health $\&$ for the prevention of continuous loss of connective tissue attachment. ${ }^{1,2}$

Orban (1948) appears to be the first to describe the term attached gingiva, he divided gingiva into 
free and attached gingiva demarcated by free gingival groove. According to him, FGG is at appropriate level of the bottom of gingival sulcus. According to the glossary of periodontal terms (1972) Attached gingiva is that portion of gingiva that extends from the base of gingival crevice to mucogingival junction. According to Glossary of Terms (2001) of the American Academy of Periodontology, attached gingiva is that portion of the gingiva that is firm, dense, stippled, and tightly bound to the underlying periosteum, tooth, and bone. ${ }^{3}$ Attached gingiva is a form of adaptive specialization. It is produced by elevation and depression in surface of gingival tissue. ${ }^{4}$ Histologically, the attached gingiva is better suited than non-keratinized mucosa to withstand mechanical irritations. The epithelium of attached gingiva is keratinized and has thin, prominent epithelial ridges. The connective tissue contains no elastic fibers. ${ }^{5}$

Assessing the width of the attached gingival (WAG) will help in assessing the risk for a periodontium to be affected by disease for which normal values need be known for that population. Hall (1982) said that the width of attached gingiva is determined by subtracting the sulcus or pocket depth from total width of gingiva. ${ }^{6}$ Methods to determine mucogingival junction are Visual method, Functional method and Visual methods after histochemistry staining. In the current study the visual method after histochemistry staining has been used to measure the width of attached gingival in Indian subpopulation.

\section{Materials and Methods:}

A total of 240 Patients attending the Outpatient department in the age group of 15 to 40 years with well aligned dentition and healthy gingival tissues were invited to participate in the study. Patient agreed to be a subject of the study. The attached gingiva was measured with a standard scale, a divider / a William's periodontal probe, a magnifying glass and iodine solution.

The iodine solution was prepared by diluting 2 gram of potassium iodide and 1 gram of iodine crystals in $60 \mathrm{ml}$ of distilled water. I odine solution was applied on subject's gingiva and alveolar mucosa by cotton pellet. Mucogingival junction was assessed visually after staining the mucogingival complex with iodine solution. Application time was as needed to result in a sharp demarcation between keratinised tissue and alveolar mucosa. ${ }^{7}$

The distance from the crest of marginal gingiva to mucogingival junction was measured by using a divider and the depth of the sulcus in the mid buccal region was measured with the help of a William's periodontal probe to get the width of attached gingiva of incisors, premolars and first molar (a total of 12 teeth) of right quadrant of maxillary and mandibular region. The divider was then placed on a scale and the measurements were recorded. The readings were rounded off to the nearest $0.5 \mathrm{~mm}$. All the measurements were made under a magnifying glass. The width of the attached gingiva was then calculated by subtracting the sulcus depth from the total width of keratinised tissue. ${ }^{8}$

\section{Results:}

Maxillary incisors had the greatest width with an average of $3.62 \mathrm{~mm}$ and mandibular molars had the least width, with an average of $1.83 \mathrm{~mm}$. Mandibular incisors had an average width of 3.31 $\mathrm{mm}$, maxillary premolars $2.06 \mathrm{~mm}$, mandibular premolars $2.02 \mathrm{~mm}$ and maxillary molars $2.02 \mathrm{~mm}$. The attached gingiva showed increase width with increase in age and was found to be more in females than males.

\section{Discussion:}

The gingiva is the part of masticatory mucosa. It covers the cervical area of teeth and alveolar process of the lower and upper jaws and acts as a strong barrier against the penetration of irritants into the periodontal tissue. The keratinized attached gingiva provides the periodontium with increased resistance to external injury, contributes to the stabilization of the gingival margin, and aids in dissipating physiological forces exerted by the muscular fibers of the alveolar mucosa on the gingival tissues. Adequate attached gingiva helps to prevent apical migration of tooth surrounding tissue and root exposure with or without periodontal pocket formation. ${ }^{9}$

The adequate amount of attached gingiva is still a topic of discussion. Due to having dense collagen fibers, it can withstand friction and the muscle tensions. Adequate WAG plays an important role in healthy periodontium. There are very few studies done to evaluate the width of attached gingiva and no studies on the Indian population. Assessing the width of the attached gingiva will help in assessing the risk for a periodontium to be affected by disease 
Table 1: Average width of attached gingiva in males and females

\begin{tabular}{|l|l|l|}
\hline & N & Mean (mm) \\
\hline Female & 134 & 3.03 \\
Male & 106 & 2.67 \\
\hline
\end{tabular}

Table 2: Average width of attached gingiva among different types of teeth

\begin{tabular}{|l|l|l|l|}
\hline \multicolumn{4}{|c|}{ Average width of attached gingiva (mm) } \\
\hline & \multicolumn{1}{|c|}{ Incisors } & \multicolumn{1}{c|}{ Premolars } & \multicolumn{1}{|c|}{ Molars } \\
\hline Maxillary & 3.62 & 2.06 & 2.02 \\
Mandibular & 3.31 & 2.02 & 1.83 \\
\hline
\end{tabular}

Table 3: Width of attached gingiva in different age groups

\begin{tabular}{|l|l|l|}
\hline Age group in years & N & Mean $(\mathrm{mm})$ \\
\hline $15-25$ & 110 & 2.40 \\
$25-35$ & 98 & 2.72 \\
$35-45$ & 32 & 2.84 \\
\hline
\end{tabular}

for which normal values need be known for that population. The present study tries to find the normal values of width of attached gingiva in a periodontally healthy Indian population. ${ }^{10,11}$

The subjects with clinically well aligned dentition and healthy gingiva were included in the study. Determining the precise position of the mucogingival junction can be difficult. It can be a discrete line or indistinct area. Iodine was used to determine the exact point at which the keratinization ends. ${ }^{12}$ The midbuccal region was chosen as a standardised landmark for all the subjects for the purpose of convenience and the fact that the minimal width of gingiva exists at this region. Factors such as probe dimension, probing force and inflammation of the tissues are known to alter the measurements. ${ }^{13}$ In the present study a standardized Williams periodontal probe was used by a single examiner. This was done in order to eliminate discrepancies in probing measurements.

There are very few studies done on the width of attached gingiva. One of the most often study quoted on width is by Bowers GM in 1963 and Ainamo in 1976. ${ }^{14,15}$ The present study measured attached gingiva with the hel $p$ of iodine solution while Talari, Ainamo and Saario used Schiller's iodine solution and orthopantomograms to measure ${ }^{16}$ Bowers found the facial attached gingival varied in different areas of the mouth as seen in the present study. Ainamo found greatest in maxillary incisors similar to our study. The least width in our study was in mandibular molars while Ainamo found it to be mandibular premolars. Ainamo and Vincent found the width of attached gingiva increases with age whereas our study. ${ }^{17,18}$ Bowers measured the widths of the facial attached gingiva in the primary and permanent dentitions of 240 subjects. Width of the attached gingiva in this study was determined by the same technique, by subtracting the sulcus probing depth (free gingiva) from the total width of the keratinized tissue (from the tip of gingival margin upto mucogingival junction). Extremes of the width of the attached gingiva by Bowers ranged from 1 to $9 \mathrm{~mm}$. However, in the present study the widths varied from 0 to $5 \mathrm{~mm}$. As in the Bowers study, the 
maxilla usually exhibited a broader zone of attached gingiva than the mandible. The average widths found in the present study was greatest in the incisor region 3.62 (3.5 to $4.5 \mathrm{~mm}$ in the maxilla, by Bowers) and 3.31 ( 3.3 to $3.9 \mathrm{~mm}$ in the mandible, by Bowers) and less in the posterior segments, with the least width in the first molar area $1.83(1.9 \mathrm{~mm}$ in the maxilla, by Bowers) and 2.02 (1.8 $\mathrm{mm}$ in the mandible, by Bowers). The values for the molars were not mentioned by Bowers et al.

\section{Conclusion:}

The width of attached gingiva is an important clinical parameter. Width of attached gingiva varies indifferent areas of the mouth with the maxillary incisors having the greatest width. There was increased width of attached gingiva with increase in age while females had a greater width of attached gingiva. Further studies should be done on periodontally healthy individuals in different population in India to get a reference value for the width of attached gingiva whether it is adequate or inadequate for making better treatment options.

\section{REFERENCES:}

1. Ainamo J, Loe H. Anatomical characteristics of gingiva. A Clinical and microscopic study of the free and attached Gingiva. J Periodontol 1996; 37:5-13.

2. Carnio J, Camargo PM, Passanezi E. Increasing the apicocoronal dimension of attached gingival using the modified apically repositioned flap technique: A case series with a 6month followup. J Periodontol 2007; 78(9):1825-30.

3. The American Academy of Periodontology. Glossary of Periodontol Terms. 2001 (4 $4^{\text {th }}$ Ed.)

4. Orban B. Clinical and histologic study of the surface characteristics of the gingival. Oral Surg Oral Med Oral Pathol 1948; 1:827-41.
5. Lozdan J, Squier CA. The histology of the mucogingival junction. J Periodontal Res 1969; 4(2):83-93.

6. Hall WB. Can attached gingiva be increased nonsurgically? Quintessence Int, 1982; 4:455-62.

7. Paola Guglielmoni, Ananya Promudthi, Dimitris N Tatakis,and Leonardo Trombelli. Intra- and I nter-examiner reproducibility in keratinized tissue width assessment with 3 methods for mucogingival junction determination. J Periodontol 2001; 72:134-9.

8. Sheehan DC, Hrapchak BB. Theory and Practice of Histotechnology. S Louis: CV Mosby. 1980; 71:8-19.

9. Itoz ME, Carranza FA. The gingiva. In: Carranza FA, Newman MG: Clinical Periodontology. $8^{\text {th }}$ Ed. Philadel phia: W.B Saunders Co. 1996; Chap 1:12-13.

10. Bowers GM. Study of the width of attached gingiva. J Periodontol 1963; 34:201-9.

11. Loe H, Ainamo J . Anatomical characteristics of gingiva: a clinical and microscopic study of the free and attached gingiva. J Periodontol 1966; 37:5-13.

12. Fasske E, Morgenroth. Comparitive stomatoscopic and histochemical studies of the A marginal gingival in man. Parodontologie 1958; 12;151-60.

13. Listgarten MA. Periodontal probing; what does it mean? J Clin Periodontol 1980; 7:165-76.

14. Bowers GM. A study of the width of the attached gingiva. J Periodontology, 1963; 34:210.

15. Ainamo J, Talari A. The increase with age of the width of attached gingiva. J Periodontal Res 1976; 11:182-8.

16. Talari A, Ainamo J . Orthopantomographic assessment of the width of attached gingiva. J Periodontal Res 1976; 11(4):177-81.

17. Ainamo A, Ainamo J. The width of attached gingiva on supraerupted teeth. J Periodontal Res 1978; 13(3):194-8.

18. Saario M, Ainamo A, Mattila K, Suomalainen K, Ainamo J The width of radiologically-defined attached gingiva over deciduous teeth. J Clin Periodontology 1995;22(12):895-98.

\section{Gain quick access to our journal online View our journal at www.nacd.in}

